\title{
Swabbing of Subcutaneous Tissues with Betadine for Prevention of Surgical Site Infection after Caesarian Section
}

\author{
Sherif Abd AlKhalek Akl, Sherif Fathi ElMekkawi, Ahmed M. El-Kotb, Adel Sayed Okily \\ Obstetrics \& Gynecology Department, Faculty of Medicine, Ain Shams University
}

\begin{abstract}
Background: The progressive increase in the incidence of caesarean birth has been a notable feature of contemporary obstetric practice and caesarean delivery is now the most frequent major surgical procedure performed in obstetrics and gynecology. In Egypt the rate of cesarean delivery is 51, $8 \%$ of all deliveries. Infectious morbidity after cesarean delivery can have a tremendous impact on the postpartum woman's return to normal function and her ability to care for her baby. Despite the widespread use of prophylactic antibiotics, postoperative infectious morbidity still complicates cesarean deliveries. Aim of the Work: To assess the efficacy of subcutaneous swabbing of cesarean section wounds with povidone iodine to prevent postoperative wound infection. Patients and Methods: The study population was randomized into 2 groups: PovidoneIodine Group: Included 275 women who underwent elective caesarian section with subcutaneous tissue irrigation with Povidone iodine 1\% solution and control Group: Included 275 women who underwent elective caesarian section without subcutaneous tissue irrigation. Results: Incidence of SSI didn't differ significantly between the Povidone-Iodine group and the Control group $(6.11 \%$ vs $8.54 \%, \mathrm{p}=0.37)$. No significant differences were found between both groups regarding the severity of SSI based on required treatment or incidence of postoperative pyrexia. Conclusion: There was no benefit of subcutaneous tissue swabbing with povidone iodine in decreasing wound infection following cesarean section.
\end{abstract}

Keywords: Subcutaneous Tissues, Betadine, Surgical Site Infection, Caesarian Section

\section{INTRODUCTION}

Cesarean delivery defines the birth via the abdominal route ${ }^{(\mathbf{1})}$. The World Health Organization (WHO) recommends that the rate of caesarean sections should not exceed $15 \%$ in any country. However, in recent years the rate has risen to a record level of $46 \%$ in china and to levels of $25 \%$ and above in many Asian countries, Latin America and the USA (2). From 1970 to 2010, the cesarean delivery rate in the United States rose from 4.5 percent of all deliveries to 32.8 percent ${ }^{(3)}$. The progressive increase in the incidence of caesarean birth has been a notable feature of contemporary obstetric practice and caesarean delivery is now the most frequent major surgical procedure performed in obstetrics and gynecology. In Egypt the rate of cesarean delivery is $51,8 \%$ of all deliveries ${ }^{(4)}$.

Cesarean delivery is one of the most common surgical procedures performed by obstetricians. Infectious morbidity after cesarean delivery can have a tremendous impact on the postpartum woman's return to normal function and her ability to care for her baby. Despite the widespread use of prophylactic antibiotics, postoperative infectious morbidity still complicates cesarean deliveries ${ }^{(5)}$.

Wound infection is an infrequent but serious complication of surgery. Postoperative infection often requires repeat surgery and prolonged hospitalization, and it may compromise ultimate surgical outcomes ${ }^{(6)}$.
If prophylactic antimicrobials are given, the incidence of abdominal wound infection following cesarean delivery ranges from 2 to 10 percent depending on risk factors ${ }^{(7)}$.

Numerous good quality trials have proved that a single dose of an antimicrobial agent given at the time of cesarean delivery significantly decreases infection morbidity ${ }^{(8)}$.

Wound irrigation with povidone-iodine, an antiseptic solution, may be useful for reducing infection, but it is of uncertain efficacy and risk. Povidone-iodine irrigation is a simple and inexpensive solution with the potential to prevent surgical site infection ${ }^{(9)}$.

Multiple studies investigated the use of povidone-iodine irrigation in multiple types of surgery. The infection rate was $2.9 \%$ in the treatment group and $15.1 \%$ in the control group ( $p<$ $0.001)$. The treatment group did not experience any interference with wound healing or adverse reactions ${ }^{(9)}$.

Povidone-iodine (Betadine) is an antiseptic solution consisting of polyvinylpyrrolidone with water, iodide and $1 \%$ available iodine; it has bactericidal ability against a large array of pathogens ${ }^{(\mathbf{1 0})}$. Although a vast amount of literature exists regarding its use as a topical antibacterial agent in surgery, its use as a prophylactic irrigation solution against surgical site infection has been examined to a lesser degree ${ }^{(9)}$.

\section{AIM OF THE WORK}


To assess the efficacy of subcutaneous swabbing of cesarean section wounds with povidone iodine to prevent postoperative wound infection.

\section{METHODS} clinical trial.

Study design: Randomized controlled

Settings: The current study was conducted in the labor ward of Ain Shams University Maternity Hospital in the period between August 2015 and August 2017.

Population: The study included a total of 550 women undergoing elective LSCS.

Research Methodology: After approval of the ethical committee, all participants in the study were given a written, informed consent, after explaining the details of the study to them. Participants included in this study had the following criteria: Age: 20 - 35 years old, elective caesarean section time from skin incision to skin closure less than 60 minute, Body Mass Index: 20$30 \mathrm{Kg} / \mathrm{m}^{2}$.

The following patients were excluded from the study: Diabetes mellitus, feverish patient, patient using steroids for chronic illness, prelabour rupture of membrane, difference in pre and postoperative hemoglobin more than $10 \%$, Patients with coagulopathies, mental condition rendering the patients unable to understand the nature, scope and possible consequences of the study.

\section{All subjects were subjected to the following:}

\section{A- Pre-enrollment assessment:}

All women were counseled regarding mode of intervention and informed consent was obtained. All women were subjected to complete history taking, routine antenatal examination, investigations especially hemoglobin test and 2 hour glucose tolerance test, and treatment of genital or urinary tract infections if diagnosed.

\section{B- Randomization and allocation concealment}

The study population was randomized using a Computer generated randomization system into 2 groups: Povidone-Iodine Group: Included 275 women who underwent elective caesarian section with subcutaneous tissue irrigation with Povidone iodine 1\% solution. Control Group: Included 275 women who underwent elective caesarian section without subcutaneous tissue irrigation with Povidone iodine $1 \%$ solution.

\section{C- Elective caesarian section:}

Preoperative: Prophylactic $1 \mathrm{gm}$ of $3 \mathrm{rd}$ generation cephalosporins 30 minutes prior to skin incision.

Operative Procedures: Skin incision was done by scalpel in Pfannenstiel manner. Subcutaneous tissue incision and division was done using scalpel. Rectus sheath division was done by scalpel with good heamostasis. Opening of the parietal peritoneum either sharp or blunt. Opening of the uterus in a $\mathrm{C}$-shaped manner. Oxytocin 5 IU by slow intravenous injection was used to encourage contraction of the uterus and to decrease blood loss. The placenta was removed using controlled cord traction and not manual removal. Closure of the uterus in two continuous layers using polyglactin 910 No 1. Closure of parietal peritoneal. Closure of the rectus sheath in a continuous fashion using polyglactin 910 No1. Good heamostasis of subcutaneous tissue using the diathermy in coagulation mood. Irrigation of the subcutaneous tissue layers using povidone iodine using Betadine filled $20 \mathrm{~cm}$ syringe in the Povidone-Iodine Group only. No insertion of subcutaneous tissue drain. No interrupted sutures in the skin. Approximating of the subcutaneous tissue using polyglactin 910 (2-0) if the tissue thickness more than $2 \mathrm{~cm}$. Closure of the skin using polypropylene (2-0) in subcuticular manner. Pericipants were followed for the incidence of surgical site infection up to 14 days following elective caesarian section, diagnosed by: Infection involved only skin and subcutaneous tissue of this incision occuring within 14 days after the operative procedure. Included at least one of the following: Purulent drainage was present (culture documentation not required) Organisms were isolated from fluid/tissue of the superficial incision At least one sign of inflammation (eg, pain or tenderness, induration, erythema, local warmth of the wound) was present. The wound was deliberately opened by the surgeon The surgeon declared the wound infected.

\section{Statistical analysis:}

Statistical analysis was performed using Microsoft Excel ${ }^{\circledR} 2007$ and statistical package for social sciences $\left(\right.$ SPSS $^{\circledR}$ version 15.0). Data was prescribed as range, mean and standard deviation (for parametric variables), range, median and interquartile range (for non-parametric variables), 
and number and percentage (for categorical variables).

\section{RESULTS}
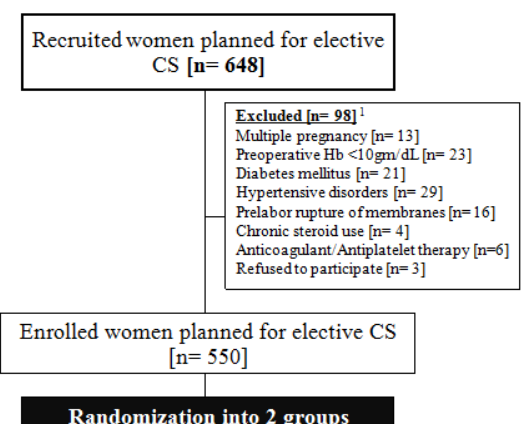

Randomization into 2 groups

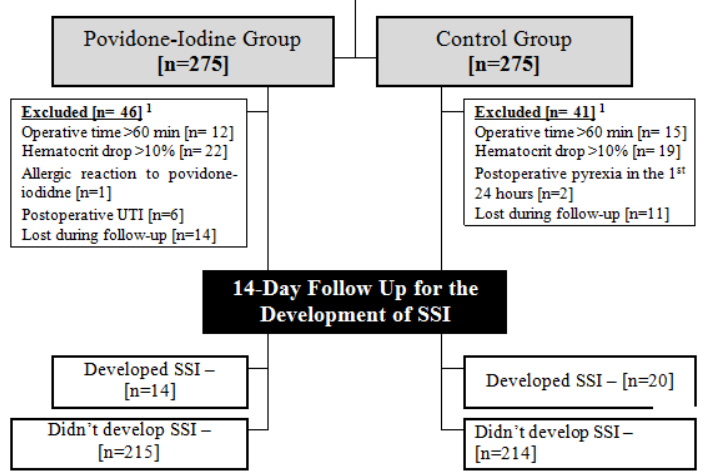

Table (1): Comparison between study groups regarding basic demographic and clinical characteristics.

\begin{tabular}{|l|c|c|c|}
\hline & $\begin{array}{c}\text { Povidone-Iodine } \\
\text { Group }\end{array}$ & $\begin{array}{c}\text { Control } \\
\text { Group }\end{array}$ & P \\
\hline Age (Yrs) & $21.0-30.0$ & $20.0-30.0$ & $0.74 \mathrm{a}$ \\
Range & $26.12 \pm 2.88$ & $25.98 \pm 3.13$ & \\
Mean \pm SD & $24.3-30.0$ & $25.4-30.0$ & $0.53 \mathrm{~b}$ \\
\hline BMI (Kg/m2) & $28.98 \pm 1.15$ & $29.08 \pm 0.90$ & \\
Range & & & \\
Mean \pm SD & $1(0-2)$ & $1(0-3)$ & $0.62 \mathrm{c}$ \\
\hline Parity & $1.14 \pm 0.84$ & $1.12 \pm 0.96$ & $0.87 \mathrm{~b}$ \\
Median (IQR) & & & \\
No. of previous CS & $37.0-40.0$ & $37.0-40.0$ & $0.33 \mathrm{~b}$ \\
\hline Gestational age & $38.49 \pm 0.70$ & $38.60 \pm 0.88$ & \\
Range & & \\
Mean \pm SD &
\end{tabular}

a Analysis using unpaired t-test; a Analysis using unpaired t-test with Welch's correction; c Analysis using Mann-Whitney U-test.

No statistically significant differences between women of both groups regarding age, body mass index, parity or gestational age.
Table (2): Comparison between study groups regarding operative and anesthetic characteristics.

\begin{tabular}{|c|c|c|c|}
\hline & $\begin{array}{c}\text { Povidone- } \\
\text { Iodine Group }\end{array}$ & $\begin{array}{l}\text { Control } \\
\text { Group }\end{array}$ & $\mathbf{P}$ \\
\hline $\begin{array}{l}\text { Ranking of surgeon } \\
\text { Consultant } \\
\text { Specialist } \\
\text { Resident }\end{array}$ & $\begin{array}{c}29(12.66 \%) \\
41(17.90 \%) \\
159(69.43 \%)\end{array}$ & $\begin{array}{l}27(11.53 \%) \\
44(18.80 \%) \\
163(69.65 \%)\end{array}$ & $0.91 a$ \\
\hline $\begin{array}{l}\text { Preoperative hemoglobin } \\
\text { concentration }(\mathrm{gm} / \mathrm{dL}) \\
\text { Range } \\
\text { Mean } \pm \mathrm{SD}\end{array}$ & $\begin{array}{c}10.30-13.40 \\
11.88 \pm 0.71\end{array}$ & \begin{tabular}{|l|}
$10.30-13.50$ \\
$11.89 \pm 0.72$ \\
\end{tabular} & 0.8 \\
\hline $\begin{array}{l}\text { Operative time }(\mathrm{min}) \\
\text { Range } \\
\text { Mean } \pm \text { SD }\end{array}$ & $\begin{array}{c}30.0-60.0 \\
45.35 \pm 6.71\end{array}$ & $\begin{array}{c}30.0-60.0 \\
44.35 \pm 7.67\end{array}$ & $0.32 b$ \\
\hline $\begin{array}{l}\text { Anesthetic modality } \\
\text { General anesthesia } \\
\text { Regional anesthesia } \\
\text { Combined }\end{array}$ & $\begin{array}{c}24(10.48 \%) \\
205(89.51 \%) \\
0(0 \%) \\
\end{array}$ & \begin{tabular}{|c|}
$28(11.96 \%)$ \\
$206(88.03 \%)$ \\
$0(0 \%)$
\end{tabular} & 0.660 \\
\hline $\begin{array}{l}\text { Hemoglobin drop }(\mathrm{gm} / \mathrm{dL}) \\
\text { Preoperative } \\
\text { Postoperative } \\
\text { Mean Paired difference }\end{array}$ & $\begin{array}{l}11.88 \pm 0.71 \\
10.89 \pm 1.03 \\
-0.99 \pm 0.55\end{array}$ & \begin{tabular}{|c|}
$11.89 \pm 0.72$ \\
$10.84 \pm 1.29$ \\
$-1.05 \pm 0.58$
\end{tabular} & $0.34 \mathrm{~d}$ \\
\hline
\end{tabular}

No statistically significant differences between women of both groups regarding surgeon ranking, preoperative hemoglobin, anesthetic modality, operative time and hemoglobin drop.

Table (3): Comparison between study groups regarding postoperative pyrexia and need for additional doses of antiobiotics, 2ry sutures or hospital stay.

\begin{tabular}{|l|c|c|c|}
\hline & $\begin{array}{c}\text { Povidone-Iodine } \\
\text { Group }\end{array}$ & $\begin{array}{c}\text { Control } \\
\text { Group }\end{array}$ & P \\
\hline Postoperative pyrexiaa & $4(1.74 \%)$ & $5(2.13 \%)$ & $0.99 \mathrm{~b}$ \\
\hline $\begin{array}{l}\text { Need for additional doses of } \\
\text { antibiotic }\end{array}$ & $12(5.24 \%)$ & $18(7.69 \%)$ & $0.71 \mathrm{~b}$ \\
\hline Need for 2ry sutures & $3(1.31 \%)$ & $4(1.70 \%)$ & $0.99 \mathrm{~b}$ \\
\hline Total hospital stay (days) & $1.07 \pm 0.66$ & $1.23 \pm 1.04$ & $0.23 \mathrm{c}$ \\
\hline
\end{tabular}

a Excluding other causes of puerperal pyrexia.

b Analysis using Fisher's exact test.

c Analysis using unpaired t-test.

Also, no significant differences were found between both groups regarding the treatment modalities used, i.e. need for additional doses of antibiotics, secondary suturing and hospital stay.

\section{DISCUSSION}

Surgical site infections (SSIs) are reported to occur in up to $8.4 \%$ of women having a caesarean section (CS) with many negative effects, including pain, prolonged hospitalization or readmission, need for antibiotics, return to theatre and increasing costs ${ }^{(\mathbf{1 0})}$. 
Extensive efforts have been made to reduce SSI after CS. These include the use of preoperative prophylactic intravenous antibiotics ${ }^{(11)}$, the use of antiseptic solutions for the cleansing of skin ${ }^{(12)}$, pre- and postoperative vaginal cleaning with an antiseptic solution ${ }^{(5)}$ and the use of negative pressure wound dressing ${ }^{\mathbf{1 3})}$.

Recommendations from the various healthcare authorities regarding intra-operative wound irrigation are conflicting. The 2017 updated CDC guidelines ${ }^{(\mathbf{1 4})}$ as well as the 2016 WHO Global Guidelines for the prevention of SSI concluded that there is insufficient evidence to recommend prophylactic epifascial intra-operative wound irrigation (pIOWI) with saline and that IOWI with diluted PVP-I could be considered but also not routinely recommended ${ }^{(2)}$. In contrast, pIOWI with saline containing antibiotics or antiseptic solutions such as povidone-iodine (PVI) are currently not recommended in the National Institute for Health and Care Excellence (NICE) Guideline ${ }^{(15)}$ due to potential adverse effects, although a critical evaluation of trials ${ }^{(16)}$ has concluded that the majority of the quality literature refutes the argument that PVI formulations have a negative impact on tissue regeneration. On the other extreme, the 2014 guidelines of the Society for Healthcare Epidemiology of America (SHEA) and the Infectious Diseases Society of America (IDSA) recommend using antiseptic incision lavage.

In this study, with the aim of assessing the efficacy of prophylactic epifascial intra-operative wound irrigation with PVI during caesarian section, 550 women undergoing elective caesarian section were randomized into a study group with intra-operative subcutaneous tissue irrigation with PVI solution during caesarian section; and a control group.

Incidence of SSI didn't differ significantly between the Povidone-Iodine group and the Control group $(6.11 \%$ vs $8.54 \%, p=0.37)$. Relative risk for incidence of SSI was lower in the Povidone-Iodine group compared to the control group; however, with statistical insignificance (0.71; 95\% CI: $0.37-1.38)$.

In the 2017 systematic review and metaanalysis by $\boldsymbol{d e}$ Jonge et $\boldsymbol{a l}$. including twenty-one study suitable for analysis, a low quality of evidence demonstrated a statistically significant benefit for incisional wound irrigation with an aqueous povidone-iodine (PVI) solution in clean and clean contaminated wounds (OR $0.31 ; 95 \% \mathrm{CI}$ $0.13-0.73 ; p=0.007) ; 50$ fewer SSIs per 1,000 procedures (from 19 fewer to 64 fewer)); whereas antibiotic irrigation had no significant effect in reducing SSIs (OR 1.16; 95\% CI 0.64-2.12; $p=$ 0.63). It was proposed by de Jonge et al. that remarkable efficacy of wound irrigation by PVI solution was due to the low microbial resistance profile due to its multiple pharmacological targets (18) compared to the emerging resistance to various antimicrobial agents, in addition to the fact that it is unlikely that pIOWI with antibiotic solutions is performed with sufficient time to attain contact time required for clinical efficacy ${ }^{(17)}$.

In the same context with de Jonge et al. in the meta-analysis of Fournel et al. which included 24 randomized controlled trials that compared intraoperative PVI lavage with no PVI in patients undergoing surgery with a total of 5004 patients (2465 patients with PVI and 2539 patients without), the rate of SSI was $8.0 \%$ in the PVI group and $13.4 \%$ in the control group. Intraoperative PVI application significantly decreased the SSI rate (RR $0.58,95 \%$ CI: $0.40-0.83 ; p=0.003) .{ }^{(18)}$

This was reflected in the 2016 WHO Guidelines Development Group (GDG) comment on their recommendations ${ }^{(2)}$ :

The GDG agreed that there is insufficient evidence to issue a recommendation for or against the saline solution irrigation of incisional wounds for the purpose of preventing SSI. The GDG also decided to suggest considering the use of irrigation of the incisional wound with an aqueous PVP-I solution. The use of the term "considering" was proposed to highlight that a decision-making process is needed, especially focusing on clean and clean-contaminated wounds. Finally, the GDG agreed to suggest that antibiotic incisional wound irrigation should not be used for the purpose of preventing SSI. The strength of these recommendations should be conditional due to the low quality of the evidence.

Another important aspect of all the previous studies and guideline recommendations is their generalization to the different surgical procedures including the various visceral surgeries, orthopedic and neurosurgical procedures. The different tissue vitality and microbiological nature of these procedures compared to that of the 
caesarian section may account for the different results obtained in studies involving patients undergoing caesarian section.

Unfortunately, marked paucity of available studies entailing caesarian deliveries is noted. To date, there have been only four studies that have focused on pIOWI in women undergoing CS with only one trial investigating the use of aqueous PVI during pIOWI.

In the 2016 Betadine Trial by Mohamed et al., 3027 women undergoing CS were allocated to receive PVI irrigation or no irrigation after closure of fascia and before skin closure. Women were followed up to four weeks to assess for SSI. The incidence of SSI was similar in the two groups (9.5\% vs $9.8 \%$, RR $0.97 ; 95 \%$ CI 0.78-1.21), thus, showing that PVI irrigation after the closure of fascia and before closure of skin had no benefit in the prevention of SSI in women undergoing CS. This agrees with the results of our study which might indicate the differing impact of PVI irrigation on the different microbiological spectrum from the nonobstetric surgical procedures ${ }^{(19)}$.

Mathelier ${ }^{(20)}$ compared the efficacy of a single intravenous dose of Cefazolin alone or combined with an antibiotic containing preclosureirrigation solution in patients undergoing cesarean section. The rate of total postoperative morbidity was 2.3 times higher in Cefazolin Group compared to Combined Cefazolin-Irrigation Group $(10.4 \%$ vs $4.5 \%)$ and morbidity at the operative site was six times higher ( $8.4 \%$ vs $1.3 \%)$.

To sum up, it seems from the evidence drawn from this study and the Betadine Trial by Mohamed et al. that pIOWI with PVI during caesarian section doesn't have an added benefit in decreasing the incidence of SSI and is, thus, not recommended at time being.

Important points of strength in this study include: First, its single-centre nature that conferred consistency with regard to surgical site preparation, surgical experience, uterine manipulation and suture materials and methods of abdominal closure. Second, staff with differing levels of experience performed the surgery, albeit under supervision for junior medical staff. Third, although the study could not be double-blinded, the research team doing the follow-up and the women's general practitioners were not aware of the group allocation. Fourth, the diagnosis of SSI was standardised according to the CDC guidelines.
However, several limitations are also present: First, while current CDC criteria recommend a follow-up time for SSIs of at least 30 days, only 14-day follow-up policy was adopted in this study due to the expected high attrition rates and incompliance to follow-up if 30-day policy was used. Second, only patients undergoing elective CS were included. Third, a larger sample size would have provided a higher degree of evidence to our recommendations.

\section{CONCLUSION}

There was no benefit of subcutaneous tissue swabbing with povidone iodine in decreasing wound infection following cesarean section.

\section{REFERENCES}

1. Berghella $V$ (2007): Cesarean delivery in: Berghella V Obstetric, Evidence Based Guidelines. 1st Edition, Informa UK Ltd.

2. WHO global guidelines for the prevention of surgical site infection (2016): http:// www. who. int/gpsc/ssi-prevention-guidelines/en.

3. Martin JA, Hamilton BE, Ventura SJ (2012): Births: final data for 2010. Natl Vital Stat Rep., 61 (1):1.

4. Demographic and Health Survey (2014): Egypt, Ministry of health and population. The DHS program, dhsprogram. com/ pubs/ pdf/ FR302/ FR302.pdf

5. Haas DM, Morgan S, Contreras K (2014): Vaginal preparation with antiseptic solution before caesarean section for preventing postoperative infections. Cochrane Database Syst Rev., 9: CD007892

6. Hedrick TL, Anastacio MM, Sawyer RG (2006): Prevention of surgical site infections. Expert Rev Anti Infect Ther., 4:223-33.

7. Chaim W, Bashiri A, Bar-David J, ShohamVardi I, Mazor M (2000): Prevalence and clinical significance of postpartum endometritis and wound infection. Infect Dis Obstet Gynecol., 8(2) :77-82.

8. American College of Obstetricians and Gynecologists (2011): Prophylactic antibiotics in labor and delivery. Practice Bulletin, https://www.ncbi.nlm.nih.gov/pubmed/21606770 
9. Chundamala J and Wright JG (2007): The efficacy and risks of using povidone-iodine irrigation to prevent surgical site infection: an evidence-based review, Canadian Journal of Surgery, 50(6): 473-481.

10. Graves N, Halton K, Curtis M et al. (2006): Costs of surgical site infections that appear after hospital discharge. Emerg Infect Dis. , 12: 831-834.

11. Mackeen AD, Packard RE, Ota E, Berghella V, Baxter JK (2014): Timing of intravenous prophylactic antibiotics for preventing postpartum infectious morbidity in women undergoing cesarean delivery. Cochrane Database Syst Rev., (12):CD009516.

12. Noorani A, Rabey N, Walsh SR et al. (2010): Systematic review and meta-analysis of preoperative antisepsis with chlorhexidine versus povidone-iodine in clean-contaminated surgery. Br J Surg., 97: 1614-1620.

13. Echebiri NC, Mcdoom MM, Aalto MM et al. (2015): Prophylactic use of negative pressure wound therapy after caesarean delivery. Obstet Gynecol., 125: 299-307.

14. Berríos-Torres SI, Umscheid CA, Bratzler DW et al. (2017): Centers for Disease Control and Prevention Guideline for the Prevention of Surgical Site Infection JAMA. Surg., 152(8):784-791.

15. National Institute for Health and Clinical Excellence (2013): Surgical Site InfectionPrevention and Treatment of Surgical Site Infection NICE Clinical Guideline 74. London: RCOG. www.nice.org.uk/Guidance/CG74

16. Banwell $H$ (2006): What is the evidence for tissue regeneration impairment when using a formulation of PVP-I antiseptic on open wounds? Dermatology, 212: 66-7.

17. de Jonge SW, Boldingh QJJ, Solomkin JS, Allegranzi B, Egger M, Dellinger EP, Boermeester MA (2017): Systematic Review and Meta-Analysis of Randomized Controlled Trials Evaluating Prophylactic Intra-Operative Wound Irrigation for the Prevention of Surgical Site Infections. Surg Infect (Larchmt), 18(4):508-519
18. Fournel I, Tiv M, Soulias M et al. (2010): Meta-analysis of intraoperative povidoneiodine application to prevent surgical site infection. Br J Surg., 97: 1603-1613.

19. Mahomed K, Ibiebele I, Buchanan J (2016): The Betadine trial - antiseptic wound irrigation prior to skin closure at caesarean section to prevent surgical site infection: A randomised controlled trial. Aust N Z J Obstet Gynaecol., 56(3):301-6.

20. Mathelier AC (1992): A comparison of postoperative morbidity following prophylactic antibiotic administration by combined irrigation and intravenous route or by intravenous route alone during cesarean section. J Perinat Med., 20:177-182. 